\title{
Surgical treatment versus medical treatment in hypertrophic obstructive cardiomyopathy
}

\author{
M. E. Rothlin, D. Gobet, T. Haberer, H. P. Krayenbuehl, \\ M. TURINA AND A. SENNING \\ Medical Department and Surgical Department A, University Hospital, Zürich, Switzerland
}

Sixty-three patients operated upon for HOCM and 49 patients selected for non-surgical treatment have been followed-up for 15 years. Pre-operatively, surgical patients had a higher left ventricular outflow tract gradient at rest and, on the average, more severe symptoms than non-surgical patients. Septal myectomy relieved the pressure gradient and symptoms more consistently than long-term treatment with $\beta$-blockers or verapamil. Within an average observation time of $71 / 2$ years, there was late deterioration or death in almost half of the non-surgical patients but in less than one-quarter in the operated patients. The 10 year mortality rate was $80 \%$ in the surgical series and $71 \%$ in the non-surgical series. In operated patients, pre-operative symptomatic status was significantly related to early and late mortality. In medically treated patients, mortality was unrelated to symptoms; however, it was significantly lower in patients receiving long term treatment with $\beta$-blockers or verapamil.

In conclusion, a high basal pressure gradient associated to limiting symptoms is a clear-cut indication for surgery. Other indications are more debatable. In medically treated patients, long-term administration of $\beta$-blockers or verapamil is beneficial even without symptoms as it appears to improve prognosis.

\section{Introduction}

Surgical treatment for hypertrophic obstructive cardiomyopathy (HOCM) was introduced at a time when the condition was thought to be nothing more than a form of aortic stenosis with the obstruction to the left ventricular ejection located below the aortic valve $^{(1)}$. Much has been learned about this condition in the meantime, and it is understood that the subvalvular obstruction to the left ventricular ejection is not the primary cause of the disease. There are patients with hypertrophic cardiomyopathy and asymmetric septal hypertrophy, presenting with the same symptoms and risk of sudden death, who do not have a left ventricular outflow-tract gradient (LVOTG). It has been established that hindrance to diastolic filling plays a very important role to the pathophysiology of $\mathrm{HOCM}^{(2)}$ and that elevated filling pressure of the left ventricle is related to the severity of symptoms. Undebated findings in HOCM are, in analogy to the situation in fixed subvalvular, valvular and supravalvular aortic stenosis, a systolic pressure difference between the left ventricular cavity

Address for correspondence: Professor M. E. Rothlin, Medical Department, University Hospital, CH-8091 Zürich, Switzerland. and the aorta, a systolic murmur and a prolongation of the left ventricular ejection time. On the other hand, left ventricular ejection is not impeded during the first part of systole in HOCM; moreover, the left ventricle ejects its content to a larger extent than normally. The true existence of obstruction to the left ventricular ejection has been challenged altogether in $\mathrm{HOCM}^{(3)}$, based on observations of an accelerated systolic ejection, with almost no flow at the time, during later systole, when LVTOG can be recorded. The latter observations are in contrast to previous intra-operative findings ${ }^{(4,5)}$ and recent echocardiographic observations ${ }^{(6)}$. The evidence in these studies was in favour of a substantial blood flow at the time, when the LVOTG exists and, hence, in favour of true obstruction to the systolic ejection. Although this matter remains controversial, it cannot be overlooked that systolic function is considerably enhanced in patients with HOCM. It is our belief, that the benefits of surgical treatment and that of B-receptor blocking agents ${ }^{(7)}$ are mediated by an effect on the systolic function, which indirectly influences diastolic function. 
Table I Clinical and haemodynamic data of the surgical and non-surgical series

\begin{tabular}{lcc}
\hline & $\begin{array}{c}\text { Surgical } \\
\text { series }\end{array}$ & $\begin{array}{c}\text { Non-surgical } \\
\text { series }\end{array}$ \\
\hline Number & 64 & 49 \\
Male/female & $41 / 22$ & $33 / 16$ \\
Age (years) & $33 \cdot 7$ & $34 \cdot 8$ \\
Mean NYHA class & $2 \cdot 5$ & 1.9 \\
LVOTG (mmHg) & 77 & 30 \\
Mean LAP (mmHg) & $15 \cdot 4$ & $12 \cdot 5$ \\
\hline
\end{tabular}

Surgical treatment consistently relieves the LVOTG and the symptoms of patients with HOCM. The effect of the myectomy operation on the course of the disease is less clear.

Medications, such as B-receptor inhibiting agents and calcium antagonists, influence the patient's symptoms and the LVOTG as well, but results are more variable. Yet the indications for medical or surgical treatment, respectively, are not the same for all patients with HOCM, the operation being mostly performed in the patients with a high LVOTG at rest and with symptoms which are not readily relieved by drug therapy. This must be kept in mind when the long-term course of surgically and medically treated patients are compared, as is done in this report.

\section{Patjents and methods}

Between 1965 and 1980, 63 patients underwent 64 myectomy operations for HOCM at the Surgical Department $A$ of the University Hospital Zürich (UHZ). All survivors have been followed for more than 1 year after the operation, the average observation period being $7 \cdot 6$ years. One patient with two myectomy operations had two postoperative courses and therefore there are 64 postoperative courses that form our surgical series.

During a similar observation time, 68 patients with HOCM were recorded at the Medical Polyclinic of the UHZ; 19 out of these were soon referred for surgery. The remaining 49 patients were followed with medical management for an average of $7 \cdot 4$ years. They constitute the non-surgical series in this report. Five of the latter patients were later referred for surgical treatment after several years of medical management. Thus $35 \%$ of all patients with HOCM recorded at the Medical Polyclinic of UHZ were eventually operated upon.

The selection criteria for surgical or non-surgical treatment are partly reflected by the baseline data of the two series depicted in Table 1. In both series, the average age was around 34 years, the male sex being predominant. In the surgical series, however, the severity of symptoms, the LVOTG and the left ventricular filling pressure were greater than in the non-surgical series.

The surgical methods of septal myectomy were previously described ${ }^{(8,9)}$. The myectomy was performed either through an apical ventriculotomy or through the aortic valve. In some patients a combined transaortic and transventricular approach had to be used. For medical treatment propranolol was administered at an average dose of $175 \mathrm{mg} /$ day in 15 patients; another 14 patients were treated with verapamil at an average dose of $360 \mathrm{mg} /$ day.

For statistical analysis of the results, Student's

Table 2 Preoperative clinical and haemodynamic data of patients with myectomy operation for HOCM. For criteria for patient groups $A, B$ and $C$ see test

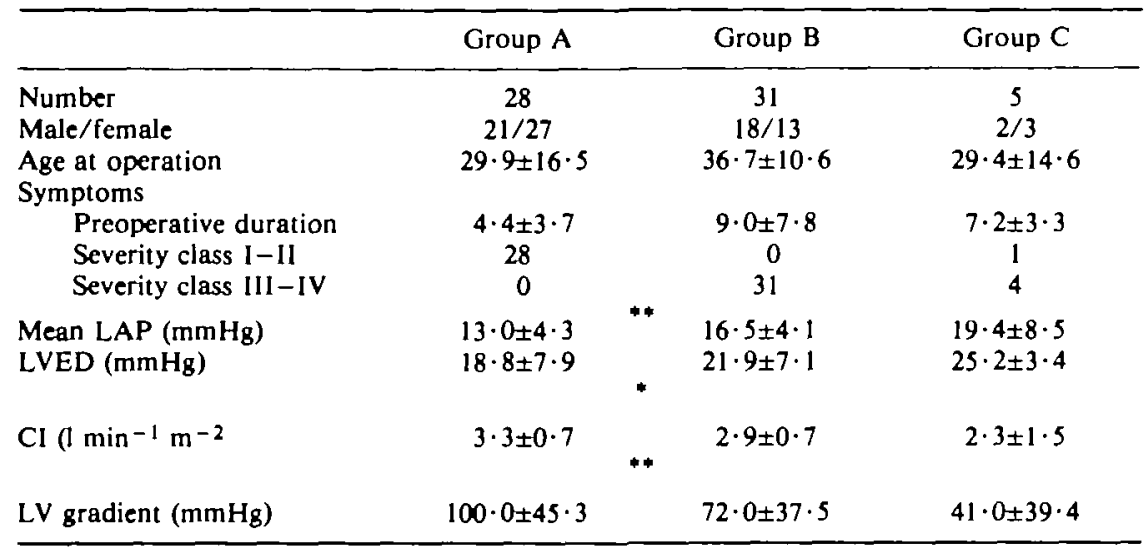

"P<0.025; "*P<0.01. 
$t$-test, the paired $t$-test and the chi-square test were used where appropriate. Survival curves were calculated according to Anderson ${ }^{(10)}$.

Results of surgical treatment as compared to the observations in the non-surgical series

According to the criteria for the operative indications the surgical series was subdivided into three patient groups (Table 2). Patients with mild or transient symptoms formed group A; patients with severe symptoms limiting their daily activity or occurring at rest formed group B. Group C comprised patients requiring mitral valve replacement or reconstruction for predominant mitral incompetence and one girl with a large left ventricular aneurysm, which was resected at the same time.

The average age of patients in group $\mathrm{A}$ was lower and the average duration of pre-operative symptoms shorter than in group B. Four out of five patients in group $C$ presented with severe symptoms and with congestive heart failure. Corresponding to the clinical observations, left ventricular filling pressure was lowest and cardiac index highest in group $\mathrm{A}$. The LVOTG, which greatly influenced the decision for surgery in mildly symptomatic patients, was significantly higher in group A.

Early and late surgical complications are tabulated in Table 3. One patient died after early postoperative tamponade with subsequent multisystem failure. Four patients required implantation of a pacemaker because of AV block early after surgery and another three because of late occurrence of AV dissocation. Mild aortic incompetence was observed in eight patients postoperatively, in another one it was more severe and required valve reconstruction. Mitral incompetence, severe residual left ventricular outflow obstruction and ventricular septal defect

Table 3 Surgıcal mortality and complications in 64 myectomy operations for HOCM

Operative death

AV block requiring pacemaker: carly 4 and late 3

Aortic incompetence

Mild

Requiring valve replacement

Mitral incompetence requiring valve replacement

Residual obstruction requiring reoperation

Ventricular septal defect made re-operation necessary in another three patients.

The pre- and postoperative catheter studies (Fig. 1) showed the elimination or a considerable reduction of the LVOTG in all patients with one exception. Left ventricular filling pressure at rest assessed by left atrial mean pressure or pulmonary capillary mean pressure was significantly reduced postoperatively; LVEDP also was lower after surgery. There was no significant difference of cardiac index between the pre- and postoperative studies.

The effect of the operation on the individual symptoms of HOCM is depicted in Figure 2. All symptoms were markedly reduced after surgery. The majority of the group A patients were asymptomatic for 5 years postoperatively (Fig. 3(a)). Ten years after surgery, one-third of the patients were again mildly symptomatic and during the later course recurrence of symptoms appeared more frequent. The symptomatic course in patients of groups $B$ and $C$ shows excellent initial improvement, with the majority of patients remaining not more than mildy symptomatic by the fifth postoperative year (Fig. 3(b) and (c)). During the later follow-up, however, a slow symptomatic deterioration is observed.

Fifteen patients of the non-surgical series received propranolol and 14 received verapamil on a longterm basis. Twenty non-surgical patients did not adhere to any medication. Detailed analysis of the course of symptoms in these patients will be reported elsewhere ${ }^{(11)}$. In Table 4 the initial functional class in patients of the non-surgical series is compared with that of the preoperative patients in the surgical cohort, and it is evident that the latter patients had considerably more symptoms. After a mean interval of about $71 / 2$ years, however, the severity of symptoms was about the same in both series. The observed changes in symptoms during the $71 / 2$ year course revealed deterioration or death in almost half of the non-surgical cases, while this occurred in less than one-quarter of the surgical series. It must be stressed, however, that 20 out of the 45 non-surgical patients did not adhere to regular medication.

Analysis of survival in the surgical and nonsurgical series is depicted in Figure 4. Ten year survival was $80 \%$ in the surgical series and $71 \%$ in the non-surgical series; the observed difference did not reach statistical significance.

Survival curves of the surgical groups A and B revealed a significant difference with a $100 \%$ survival at 10 years for group $A$ and a $62 \pm 12 \%$ survival for group B. Thus, after the myectomy operation, prognosis was dependent on the severity of pre- 

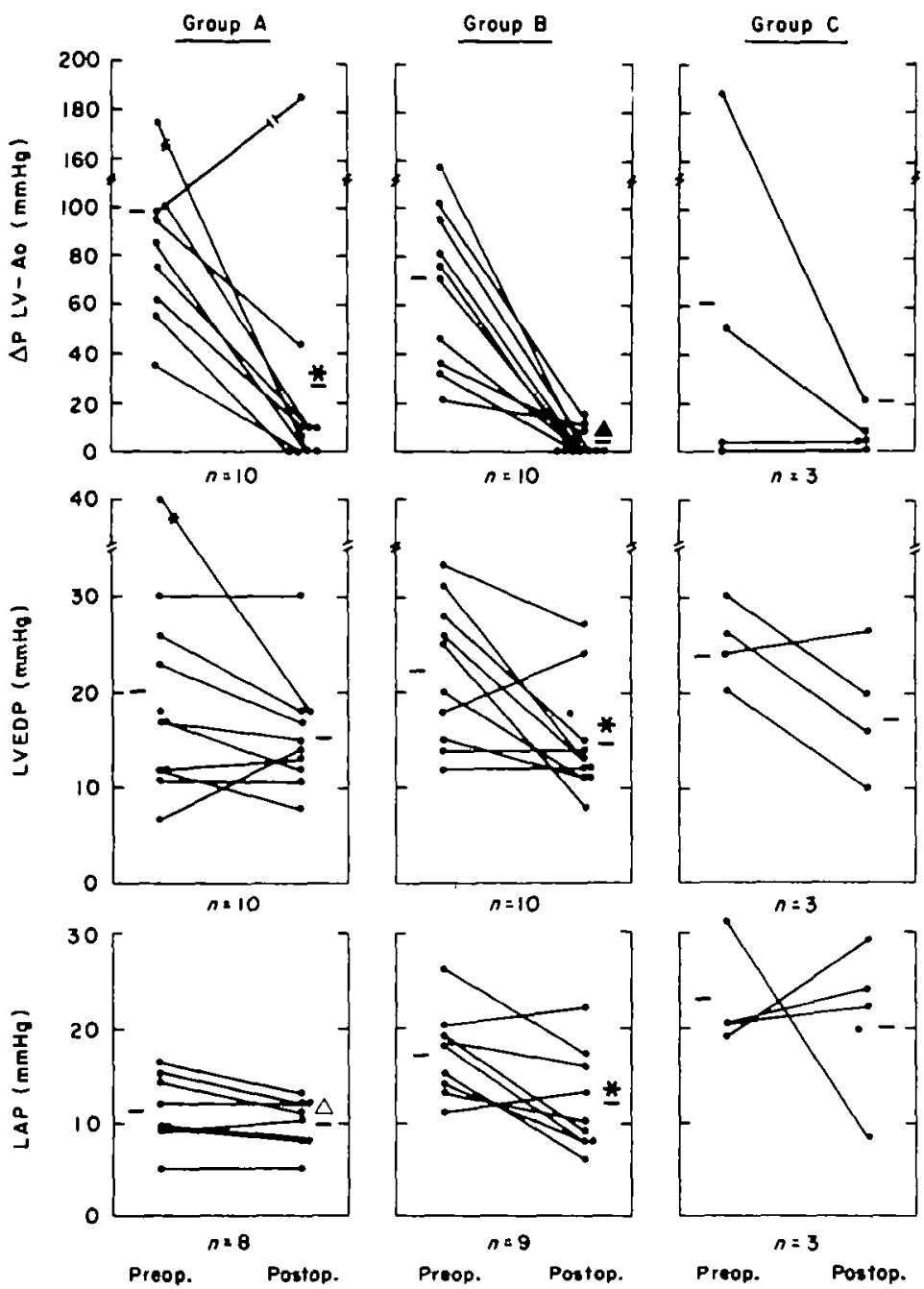

Figure I Effect of myectomy operation on LVOTG ( $\triangle$ PLV-Ao), left ventricular end-diastolic pressure (LVEDP) and left atrial pressure or pulmonary capillary pressure (LAP) in group $A, B$ and $C$ patients with HOCM. -, group mean value; $\triangle, P<0 \cdot 05 ; \star, P<0 \cdot 01 ; \triangle, P<0 \cdot 0005$.

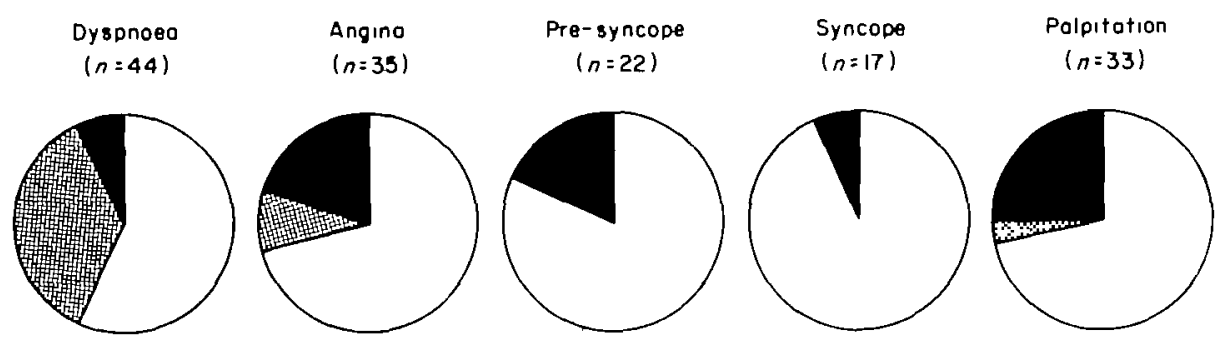

Figure 2 Effect of myectomy operation on the individual symptoms of patients with HOCM. White area indicates symptom disappeared; stippled area indicates symptom improved; black area indicates symptom unchanged. 

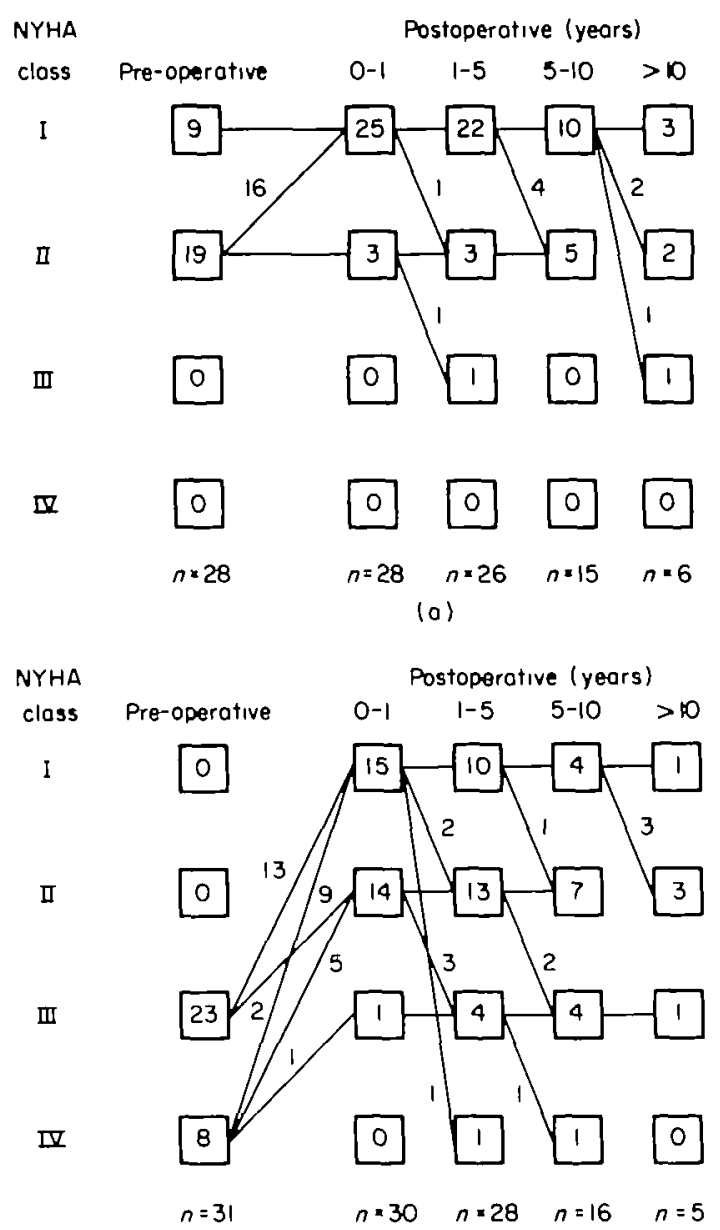

(b)

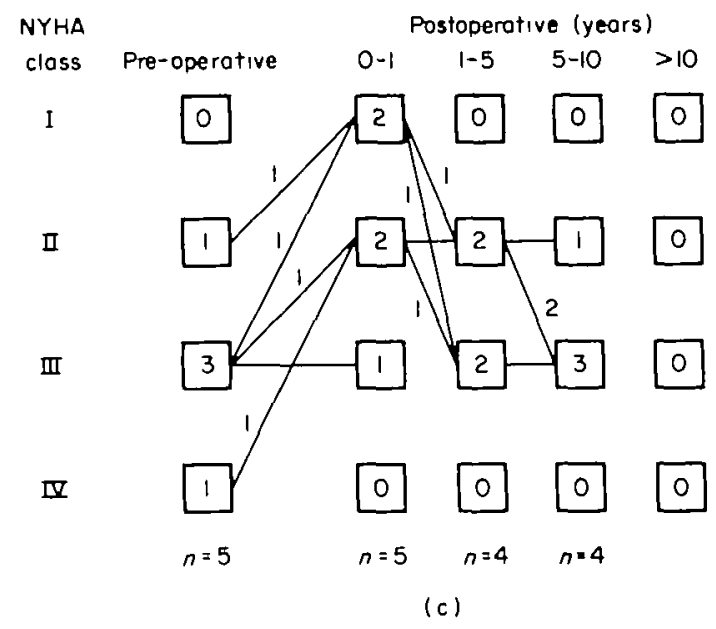

Figure 3 Symptomatic course after septal myectomy operation in patients with HOCM in (a) group A, (b) group B and (c) group C. operative symptoms, while in the non-surgical series severity of symptoms was not significantly different in survivors (average of NYHA class $1 \cdot 8$ ) compared to deceased patients (average of NYHA class $2 \cdot 1$ ).

In the non-surgical series there was a significant difference of survival dependent on the presence of long-term medication. Ten year survival of patients receiving propranolol or verapamil was $78 \%$ as compared to $49 \%$ in patients who were not taking a regular drug treatment.

The causes of death in the surgical and nonsurgical series is listed in Table 5. Sudden unexpected death occurred in only three of the 11 deceased patients in the surgical series but it occurred in 10 of the 14 in the non-surgical group.

Holter monitoring in 30 patients of the UHZ surgical series performed in the late follow-up at an average interval of $6 \frac{1}{2}$ years after operation revealed multiform ventricular extrasystoles, bigeminy, couplets or ventricular tachycardia in 12 patients (Table 6). It may be seen that patients of group A had the highest incidence of complicated ventricular arrhythmia. None of the patients with the more severe degree of ventricular arrhythmia has died during a subsequent interval of three years, although no antiarrhythmic medication was routinely administered.

\section{Discussion}

The postoperative follow-up of patients with HOCM subjected to septal myectomy is discussed and compared to the course of HOCM in patients selected for conservative management at an institution which refers $35 \%$ of its patients with this disease to surgery. This proportion of operative to non-operative treatment is very similar to that reported from the Mayo Clinic ${ }^{(12)}$. The principal indications for conservative treatment were no or mild symptoms only after medical treatment and absence of a considerable LVOTG at rest. By contrast, a large LVOTG and severe symptoms were the most important factors in favour of surgery. These criteria for the selection of patients for the two forms of management are well reflected by the baseline data of the surgical and non-surgical series presented. Therefore, it has to be stressed again, that in this report two types of treatment are discussed in two selected groups of patients with HOCM. Moreover, it must be kept in mind that only 29 of the 49 patients in the non-surgical series adhered to longterm medication. 
Table 4 Long-term course of symptoms in HOCM

\begin{tabular}{|c|c|c|c|c|}
\hline \multirow[b]{2}{*}{ NYHA class } & \multicolumn{2}{|c|}{$\begin{array}{l}\text { Non-surgical group } \\
\qquad(n=49)\end{array}$} & \multicolumn{2}{|c|}{$\begin{array}{l}\text { Surgical group } \\
\quad(n=64)\end{array}$} \\
\hline & $\begin{array}{l}\text { Inttial } \\
\text { examination }\end{array}$ & $\begin{array}{c}\text { Last } \\
\text { examination }\end{array}$ & $\begin{array}{l}\text { Preoperative } \\
\text { examination }\end{array}$ & $\begin{array}{c}\text { Last } \\
\text { postoperative } \\
\text { examination }\end{array}$ \\
\hline 1 & 9 & 18 & 9 & 24 \\
\hline 11 & 37 & 10 & 21 & 23 \\
\hline III & 3 & 7 & 25 & 6 \\
\hline IV & 0 & 0 & 9 & 0 \\
\hline Dead & & 14 & & 11 \\
\hline Average class & $1 \cdot 88$ & $1 \cdot 69$ & $2 \cdot 56$ & $1 \cdot 66$ \\
\hline Average interval (years) & & $7 \cdot 4$ & & $7 \cdot 6$ \\
\hline
\end{tabular}

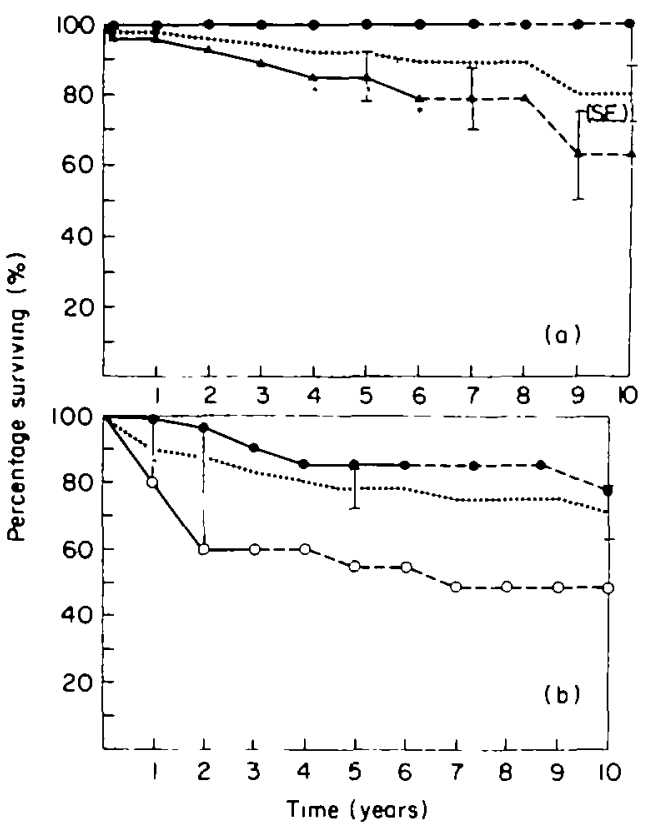

Figure 4 (a) Survival curves of group A and group $B$ patients in the surgical series. ......, All patients; $\bullet-\bullet, N Y H A$ classes I and II, group A; $\mathbf{\Lambda}-\boldsymbol{\Lambda}$, NYHA classes III and IV, group B; $\star, P<0.05$ group A to group B. (b) Survival curves of patients in the non-surgical series with or without long-term medication. ......, All patients; with medication; medication; $\star, P<0 \cdot 05$.
The surgical mortality of one death out of 64 myectomy operations compares favourably to that reported earlier ${ }^{(12-16)}$. However, in surgical series operated more recently a very low mortality has been reported by others ${ }^{(17-19)}$. Surgical complications observed in this series have previously been discussed in relation to operative technique ${ }^{(9)}$. It was found that the myectomy operation through an apical ventriculotomy carries a higher risk of AV block, while the transaortic approach caused a higher incidence of aortic valve incompetence. The latter complication, associated to the surgical technique preferred by most surgeons at present, was of mild degree with one exception.

In agreement with previous reports from this $(9,20)$ and other institutions ${ }^{(12-15,21,22)}$, the myectomy operation abolished the LVOTG and reduced left ventricular filling pressure in most patients. Symptoms remained improved for 5 years with few

Table 5 Cause of death in patients with HOCM as related to the type of treatment

\begin{tabular}{lcc}
\hline & $\begin{array}{c}\text { Surgical } \\
\text { series }\end{array}$ & $\begin{array}{c}\text { Non-surgical } \\
\text { series }\end{array}$ \\
\hline Sudden unexpected death & 3 & 10 \\
Congestive heart failure & 5 & 3 \\
Surgical death & 1 & 0 \\
Myocardial infarction & 1 & 0 \\
Arrhythmia and shock & 1 & 0 \\
Traffic accident & 0 & 1 \\
\hline
\end{tabular}


Table 6 Ventricular arrhythmia recorded by 24 h Holter monitoring in patients after myectomy operation for HOCM

\begin{tabular}{lccc}
\hline & $\begin{array}{c}\text { Group A } \\
(n=14)\end{array}$ & $\begin{array}{c}\text { Group B } \\
(n=13)\end{array}$ & $\begin{array}{c}\text { Group C } \\
(n=3)\end{array}$ \\
\hline $\begin{array}{l}\text { Postoperative interval } \\
\text { (years) }\end{array}$ & $\begin{array}{c}6 \cdot 7 \\
(1-14)\end{array}$ & $\begin{array}{c}6 \cdot 2 \\
(3-15)\end{array}$ & $\begin{array}{c}4 \\
(1-6)\end{array}$ \\
$\begin{array}{l}\text { No VES } \\
\text { Uniform VES }\end{array}$ & 0 & 0 & 1 \\
$\quad \begin{array}{l}\text { Uniform per hour } \\
\quad>30 \text { per hour }\end{array}$ & 6 & 5 & 0 \\
$\begin{array}{l}\text { Multiform VES } \\
\text { Bigemini or couplets }\end{array}$ & 1 & 4 & 1 \\
VT & 2 & 0 & 0 \\
& 3 & 3 & 1 \\
\end{tabular}

VES = ventricular extrasystole; VT = ventricular tachycardia.

exceptions. Regular examinations up to 15 years postoperatively revealed, however, slow recurrence of symptoms in a considerable number of patients. The functional status at the end of the $71 / 2$ year observation period was almost identical in surgical and non-surgical series. Compared to symptoms at entry into observation, two-thirds of the operated patients remain considerably improved or symptomfree after $71 / 2$ years, while this is the case in only onethird of the non-surgical series. On the other hand, less than one-quarter of patients in the surgical group experienced deterioration or died during the same observation time; without surgery, however, this was the case in half of the patients.

The 10 year survival rate in the surgical series was $80 \%$ as compared to $71 \%$ in the medical group; however, this difference did not reach statistical significance. It is of interest to note that all patients who had transient or mild chronic symptoms preoperatively survived 10 years postoperatively, and only one patient of this group A died - 15 years after his operation, of slowly progressive myocardial failure. On the other hand, patients with symptoms

* limiting their activity before surgery, who form group B, had a 10 year survival of $62 \%$ only. The highest late mortality was observed in the patients with additional mitral valve surgery or left ventricular aneurysmectomy. In non-surgical patients the mortality was not related to the symptomatic status at entry into observation. Earlier reports on the natural course of HOCM, however, revealed a higher mortality in severely symptomatic patients ${ }^{(23)}$.

In non-surgical patients the administration of $\beta$ receptor inhibitors or verapamil apparently improved survival. This is a most interesting observation, but it must be kept in mind that this study was not prospective and therefore the difference in mortality, which occurred within the first 2 years of observation only, may be due to factors other than long-term medication. Confirmation of this beneficial effect of $\beta$-receptor inhibitors and verapamil must therefore be awaited.

Unexpected sudden death is the most common cause of death in HOCM not subjected to septal myectomy operation $(1,23,25)$ and the non-surgical series presented here confirm this. After surgery, however, unexpected sudden death is uncommon, causing only three of 11 fatalities. The results reported here, and those of previous reports on the follow-up of operated patients with HOCM, reveal 20 unexpected sudden deaths during a total of 2028 patient-years, i.e. a yearly rate of $1 \cdot 0 \%(12-15,21,22)$. In the very large experience of the Royal Postgraduate Medical School on the natural course of hypertrophic cardiomyopathy, 32 sudden deaths were reported within 1524 patient-years, corresponding to a yearly rate of $2 \cdot 1 \%{ }^{(1)}$. A relation between ventricular arrhythmia and sudden death has been noted in the latter report. In contrast to this, our limited experience with Holter monitoring in patients after septal myectomy for HOCM revealed the highest incidence of complicated ventricular arrhythmia in patients of group $A$, in whom not a single unexpected sudden death occurred. It is possible that complicated ventricular arrhythmia does not have the same meaning in different forms of the disease or after a septal myectomy operation.

The most common cause of death in the surgical series is progressive congestive heart failure. This complication occurred only years after the operation. Moreover, in several patients with pre-operative congestive heart failure this complication was relieved by surgical intervention for a substantial time period. It therefore seems unlikely that congestive heart failure occurring late postoperatively is caused by myocardial injury due to the septal myectomy operation.

In conclusion, the septal myectomy operation is clearly indicated in patients presenting with a LVOTG at rest of $50 \mathrm{mmHg}$ or more if they have symptoms limiting their normal activity in spite of adequate medical treatment. There is no conclusive evidence yet whether myectomy operation is beneficial for patients with mild symptoms presenting with a very high LVOTG, although the post operative course has been very favourable in this subset. Repetitive syncope, previous cardiac arrest or 
sudden death in siblings of the patient may be in favour of surgical treatment.

If predominant mitral valve incompetence is present, mitral valve replacement seems to be the operative method of choice because of the high incidence of recurrence of mitral incompetence observed after reconstruction. In patients who do not meet the criteria for surgery, long-term medical treatment is beneficial even in the absence of symptoms because it appears to improve the prognosis.

\section{References}

(1) Goodwin JF, Hollman A, Cleland WP, Teare D. Obstructive cardiomyopathy simulating aortic stenosis. Br Heart J 1960; 22: 403.

(2) Goodwin JF. The frontiers of cardiomyopathy, $\mathrm{Br}$ Heart J 1982; 48: 1 .

(3) Murgo JP, Alter BR, Dorethy JF, et al. Dynamics of left ventricular ejection in obstructive and nonobstructive hypertrophic cardiomyopathy. J Clin Invest 1980; 66: 1369.

(4) Pierce GE, Morrow AG, Braunwald E. Idiopathic hypertrophic subaortic stenosis. III. Intraoperative studies of the mechanism of obstruction and its hemodynamic consequences. Circulation 1964; 30: IV-152.

(5) Ross J Jr, Braunwald E, Gault JH, Mason DT, Morrow AG. The mechanism of the intraventricular pressure gradient in Idiopathic hypertrophic subaortıc stenosis. Circulation 1966; 34: 558.

(6) Pollick Ch, Christopher D, Morgan D, et al. Muscular subaortic stenosis: the temporal relationship between systolic anterior motion of the anterior mitral leaflet and the pressure gradient. Circulation 1982; 66: 1087.

(7) Hess OM, Grimm J, Krayenbuhl HP. Diastolic function in hypertrophic cardiomyopathy: effects of propranolol and verapamil on diastolic stiffness. Eur Heart J 1983; 4 (Suppl F): 47-56.

(8) Senning $\AA$. Transventricular relief of idiopathic hypertrophic subaortic stenoses. J Cardiovasc Surg 1976; 17: 371 .

(9) Senning A, Rothlin M. Chirurgie bei hypertropher obstruktiver Kardiomyopathie. Kardiol 1983; in press.

(10) Anderson RP, Bonchek LI, Grunkemeier GL, et al. The analysis and presentation of surgical results by actuarial methods. J Surg Res 1974; 16: 224.

(11) Haberer TR, Hess OM, Krayenbüh HP. Spontanverhauf der hypertrophen, obstruktiven Kardiomyopathie im Vergleich zu Propranolol und Verapamil. Jahrestagung Ges Herz- Kreislaufforsch 1983; in press.

(12) Tajik AJ, Giuliani ER, Weidman WH, et al. Idiopathic hypertrophic subaortic stenosis, long-term surgical follow-up. Am J Cardiol 1974; 34: 815.

(13) Agnew TM, Barrat-Boyes BG, et al. Surgical resection in idiopathic hypertrophic subaortic stenosis with a combined approach through aorta and left ventricle.
A long-term follow-up study in 49 patients. Idiopathic hypertrophic subaortic stenosis. J Thorac Cardiovasc Surg 1977; 74: 307.

(14) Maron BJ, Merrill WH, Freier PA, et al. Long-term clinical course and symptomatıc status of patients after operation for hypertrophic subaortic stenosis. Circulation 1978; 57: 1205.

(15) Wigle ED, Adelman AG, Felderhof $\mathrm{CH}$. Medical and surgical treatment of the cardiomyopathies. Circ Res 1974; 34/35: II-196.

(16) Schulte HD, Bircks W, Körfer R, Kuhn H. Surgical aspects of typical subaortic and atypical midventrıcular hypertrophic obstructive cardiomyopathy (HOCM). Thorac Cardiovasc Surg 1981; 29: 375.

(17) Bircks W, Schulte HD. Surgical treatment of hypertrophic obstructive cardiomyopathy with special reference to complications and to atypical hypertrophic obstructive cardiomyopathy. Eur Heart J 1983; 4 (Suppl F): 187-190.

(18) Binet JP, David Ph, Piot JD. Surgical treatment of hypertrophic obstructive cardiomyopathies. Eur Heart J 1983; 4 (Suppl F): 191-195.

(19) Reis RL, Hannah H, Carley JE, Pugh DM. Surgical treatment of idiopathic hypertrophic subaortic stenosis (lHSS). Circulation 1977; 56 (Suppl II): II-128.

(20) Rothlin M, Wirz P, Preter B, et al. Chirurgische Resultate bei muskularer Subaortenstenose. Disch Med Wochenschr 1969; 94: 2979.

(21) Shah PM, Adelman AG, Wigle ED, et al. The natural (and unnatural) history of hypertrophic obstructive cardiomyopathy. Circ Res 1974; 34: II-179.

(22) Loogen F, Krelhaus W, Kuhn $H$. Verlaufsbeobachtungen der hypertrophischen obstruktiven Myokardiopathie (HOCM). Z Kardiol 1976; 65: 511.

(23) Frank S, Braunwald E. Idiopathic hypertrophic subaortic stenosis. Clinical analysis of 126 patients with emphasis on the natural history. Circulation $1968 ; 37: 759$.

(24) McKenna W, Deanfield J, et al. Prognosis in hypertrophic cardiomyopathy: role of age and clinical, electrocardographic and hemodynamic features. Am J Cardiol 1981; 47: 532.

(25) Maron BJ, Roberts WC, Epstein SE. Sudden death in hypertrophic cardiomyopathy: a profile of 78 patients. Circulation 1982; 65: 1388.

Schulte We know, Dr Rothlin, that Professor Senning preferred to perform a transventricular approach for resection of the myocardial obstruction. Could you find any differences according to your long-term follow-up data in regard to the transaortic or transventricular approach?

Rothlin This question has been investigated and it was discussed a year ago. It is true that in the early series most patients were operated using a transventricular approach; in the later series, and at 
present, a transaortic approach, which has been varied a little bit in the last few years, is preferred. If we look at the results, we may say that the complete abolition of the left ventricular outflow tract gradient has been superior in the patients operated using a transventricular approach or a combined transventricular and transaortic approach. I may say that in the early operation around 12 to $14 \mathrm{~g}$ of myocardium were removed. If we look, on the other hand, at the complications, as I have shown, aortic incompetence was more frequent with transaortic operations and AV block more frequent with the transventricular approach. Now, as far as the late results are concerned, it is very difficult to give you an answer because we have used only the transventricular approach in patients with a follow-up of more than 7 years, while in the other patients we do not have such a long follow-up, with one exception. The late deterioration occurs only 6 years or later after the operation. Therefore, we do not know whether patients operated through the aortic valve will have more late problems arising in the future.

Murgo I apologize if I do not remember where you gave the details of the medical treatment group, but since Dr Frank had shown that the efficacy of therapy is related to dose and the time of evaluation, and Dr Goodwin that various combinations are important if arrhythmia is present or not, perhaps you can give us some details as to medical treatment.

- Rothlin I apologize, I probably forgot to give you these details. They are important, of course. The medical treatment comprised 14 patients on propranolol at an average dosage of $175 \mathrm{~m} \mathrm{~g} /$ day. Some patients had other $\beta$-blockers but in an equivalent dosage. The verapamil dosage was on average 360 $\mathrm{mg} /$ day. It must be said that out of the 49 patients who primarily had some medical treatment, 20 patients did not adhere for a very long time to one or other of these medications. So it is certainly difficult to compare these medications with surgical treatment, because an operation you can perform and then the patient stays with it. With medications it depends very much on what your patient does. It is again another story what he tells you that he did, if you do not measure serum levels and so on.
Loogen We have discussed operative treatment versus conservative treatment but we have not mentioned one therapeutic alternative, which is used in several places in our country. That is the implantation of a pacemaker. Have you any experience with this method and what is your opinion of this?

Rothlin We have no therapeutic experience of this, but we tested pacemaker stimulation about 12 to 15 years ago in patients with hypertrophic obstructive cardiomyopathy. It was first observed by Hassenstein that if you place a pacemaker electrode in the apex of the right ventricle and you pace the patient from there, the gradient diminishes or disappears. We have confirmed this, but in placing a catheter in different positions, mainly in the right ventricular outflow tract, to our surprise we observed that the gradient was greatly increased. We could consistently show that by placing the catheter in the right place, it was possible by ventricular pacing to increase the pressure gradient. This may be important if one has to treat a patient with an intracavitary pacemaker. Now, I believe, you have also had some experience with pacing and that in your experience, and also in one of my colleagues' patients, ventricular fibrillation developed. Therefore, 1 did not really go on along this line. If pacing is necessary in HOCM, one should use a pacemaker with atrial and ventricular stimulation if this is possible.

Goodwin I would like to take this opportunity on my own behalf and on behalf of all the invited participants of thanking Professor Loogen and Professor Kuhn and congratulate them warmly on one of the best workshops I have ever attended. It has fulfilled all the best ideals, I think, of a workshop, which are those of small numbers of informed people getting together and discussing freely and asking questions. Unless you ask the right questions, you never get any answers at all. Everyone that I have heard has asked very pertinent and important questions and $I$ think we owe a great debt to Professor Loogen and Professor Kuhn and also, incidentally, to Pharma Schwarz, who have done so much to oil the wheels and make everything as superb as it has been. Thank you very much! 
